\title{
Reg (regenerating) gene overexpression in islets from non-obese diabetic mice with accelerated diabetes: role of IFN $\beta$
}

\author{
R. Planas • A. Alba • J. Carrillo • M. C. Puertas • \\ R. Ampudia $\cdot$ X. Pastor $\cdot$ H. Okamoto $\cdot$ S. Takasawa \\ W. Gurr $\cdot$ R. Pujol-Borrell $•$ J. Verdaguer $\cdot$ M. Vives-Pi
}

Received: 30 March 2006 / Accepted: 1 June 2006 / Published online: 10 August 2006

(C) Springer-Verlag 2006

\begin{abstract}
Aims/hypothesis The expression of IFN $\beta$ in beta cells results in accelerated type 1 diabetes. The REG family of beta cell proliferation factors have been described as autoantigens in autoimmune diabetes. The aim of this study was to determine the effect of IFN $\beta$ on Reg expression, and the implications of this in terms of autoimmunity.

Methods Reg gene expression was determined in islets from non-obese diabetic (NOD) RIP-HuIFN $\beta$ mice by cDNA microarray, quantitative real-time PCR and immunohistochemistry. The effect of IFN $\beta$ on Regl and Reg2 expression was assessed in the NOD insulinoma cell line NIT-1. IL-6, known to induce Reg expression, was measured in the insulitis microenvironment. Morphological studies were carried out to determine islet enlargement in this model.
\end{abstract}

\section{H. Okamoto}

Department of Advanced Biological Sciences for Regeneration, Tohoku University Graduate School of Medicine,

Sendai, Miyagi, Japan

S. Takasawa

Department of Biochemistry,

Tohoku University Graduate School of Medicine,

Sendai, Miyagi, Japan

W. Gurr

Section of Endocrinology, Yale University School of Medicine, New Haven, CT, USA

R. Planas $\cdot$ A. Alba $\cdot$ J. Carrillo $\cdot$ M. C. Puertas $\cdot$ R. Ampudia X. Pastor $\cdot$ R. Pujol-Borrell $\cdot$ J. Verdaguer $\cdot$ M. Vives-Pi $(\square)$

Laboratory of Immunobiology for Research and Diagnostic Applications (LIRAD), Blood and Tissue Bank, Germans Trias i Pujol University Hospital,

P.O. Box 72, 08916 Badalona, Barcelona, Spain

e-mail: mvives.liradbst.germanstrias@gencat.net
Results Reg2 was upregulated in islets from the NOD RIPHuIFN $\beta$ mice at the onset of the autoimmune attack. IFN $\beta$ upregulates Reg1 and Reg2 genes in NIT-1 cells. The expression of $I l 6$ was increased in islets from transgenic mice and in NIT-1 cells exposed to HuIFN $\beta$. Moreover, islets from transgenic mice were enlarged compared with those from wild-type mice.

Conclusions/interpretation Reg overexpression correlates well with the acceleration of diabetes in this model. The upregulation of Reg suggests that islets try to improve hyperglycaemia by regenerating the cells lost in the autoimmune attack. Reg expression is regulated by several factors such as inflammation. Therefore, the overexpression of an IFN $\beta$-induced autoantigen (REG) in the islets during inflammation might contribute to the premature onset of diabetes.

Keywords Diabetes · IFN $\beta$ Islets · NOD mice $\cdot$ REG . Regenerating gene
Abbreviations
$\mathrm{H} / \mathrm{E} \quad$ haematoxylin and eosin
IIF indirect immunofluorescence
NOD non-obese diabetic
SCID severe combined immune deficiency

\section{Introduction}

Type 1 diabetes results from a combination of genetic, immunological and environmental factors [1]. Although the aetiology of the disease is believed to have a major genetic component, environmental factors, such as viruses, may be determinants [2-4]. Type I interferons-antiviral cytokines - are mediators in type 1 diabetes [5-7]. The trans- 
genic expression of the human gene for $\operatorname{IFN} \beta(\operatorname{HuIFN} \beta)$ in islet beta cells [8] accelerates autoimmune diabetes in nonobese diabetic (NOD) mice [9] and breaks the tolerance in non-diabetes prone strains. In this paper we report that the beta cell regeneration factor REG, also described as a diabetes autoantigen $[10,11]$ is overexpressed in islets from RIP-HuIFN $\beta$ transgenic mice.

Regenerating gene (Reg) was isolated from a cDNA library of rat regenerating islets [12]. REG family proteins, involved in liver, pancreatic, gastric and intestinal cell proliferation, belong to a conserved protein family sharing structural and functional properties. The increase of Reg expression in cancer [13, 14], inflammatory bowel disease [15] and autoimmune diabetes [10] could promote cell growth.

In mice, Reg1 and Reg2 genes encode proteins expressed in the pancreatic exocrine tissue and in regenerating islets $[16,17]$. After partial pancreatectomy, experimental diabetes is improved by administering REG [18]. NOD mice expressing Regl in beta cells show a delay in the onset of diabetes [19], whereas islets from Reg knockout mice showed a lower proliferative response [19]. Moreover, in NOD mice, diabetes improves following the administration of REG [20]. HIP/PAP, a REG family protein, is overexpressed in islets from patients with recent-onset type 1 diabetes and acts as T-cell autoantigen in NOD mice [10]. Type 1 and type 2 diabetes patients have autoantibodies to REG that delay beta cell proliferation [11]. Although Reg upregulation may reflect the effort of the islets in trying to repair the destruction of beta cells, REG proteins may act as autoantigens contributing to activate lymphocytes against REG, off-balancing the loss and generation of beta cells, and influencing diabetes onset.

Factors like nicotinamide, glucocorticoids, diet [21] and IL-6 [10], IL-8 [22] and IFN $\gamma$ cytokines [14] regulate Reg expression. Our hypothesis is that an initial inflammation driven by IFN $\beta$ can upregulate $\operatorname{Reg}$ genes in an attempt to regenerate beta cells, possibly contributing to accelerate autoimmunity. In this study, we compared the expression of $R e g$ genes in NOD mice and NOD RIP-HuIFN $\beta$ transgenic mice (a model of accelerated autoimmune diabetes) and correlated them with alterations in islet morphology.

\section{Materials and methods}

\section{Cell lines}

The NOD insulinoma cell line NIT-1 (CRL-2055; ATCC, Manassas, VA, USA) was cultured as described [23] and supplemented with HuIFN $\beta \quad(50,000 \mathrm{U} / \mathrm{ml}$; Betaferon; Schering, Madrid, Spain) for $72 \mathrm{~h}$. To confirm the effect of HuIFN $\beta$, MHC class I production was assessed by flow cytometry [24] with an anti-MHC class I antibody (H-2, M1/42.3.9.8.HKJ/TIB-126; ATCC) and an FITC-labelled goat anti-rat secondary antibody (SBA, Birmingham, AL, USA). Data were analysed with a FACScan Cell Analyzer (BD Biosciences, San Jose, CA, USA) and CellQuest software (BD Biosciences).

Animals

Transgenic mice expressing the human gene for IFN $\beta$ under the control of the rat insulin I promoter (RIPHuIFN $\beta$ ) were generated by backcrossing the original C57BL6/SJL RIP-HuIFN $\beta$ transgenic mice with CD-1 mice [25]. NOD and NOD-severe combined immune deficiency (SCID) mice [26] - unable to produce mature T and B lymphocytes-were obtained from The Jackson Laboratory (Bar Harbor, ME, USA). Transgenic NOD mice were generated by backcrossing CD-1 RIP-HuIFN $\beta$ ten times to the NOD background. The acquisition of the genetic background was controlled by the analysis of microsatellites [8]. NOD RIP-HuIFN $\beta$ mice were crossed onto the NOD-SCID strain to generate NOD-SCID RIPHuIFN $\beta$. Non-transgenic littermates were used as controls for each strain of mice. Only female mice were analysed in this study. Mice were kept under specific pathogen-free conditions in a 12-h light-darkness cycle with free access to standard diet. For diabetes assessment, mice were monitored daily for glycosuria (Chroma 1 Glucose strips; Menarini, Barcelona, Spain). Principles of laboratory animal care (NIH publication) and the guidelines for the use and care of laboratory animals of the Generalitat de Catalunya (Spain) were followed.

Insulitis score

To determine the degree of insulitis, pancreases were snap frozen in an isopentane/cold acetone bath. Five $\mu \mathrm{m}$ cryostat sections performed at five non-overlapping levels were stained with haematoxylin and eosin $(\mathrm{H} / \mathrm{E})$. Groups of three to six mice were analysed at the age of 4 and 14 weeks, assessing a minimum of 20 islets per mouse. Insulitis was scored as described elsewhere [27]: 0, no insulitis; 1, peri-insular; 2 , mild insulitis $(<25 \%$ of the infiltrated islet); $3,25-75 \%$ of the islet infiltrated; 4 , total islet infiltration.

Islet isolation and purification

Pancreases were digested with collagenase (Worthington, Lakewood, NJ, USA) and islets were hand picked under a stereomicroscope as described [28]. To prepare cytosmears, freshly isolated islets were mechanically disrupted and centrifuged onto glass slides [29]. 
cDNA microarray

Total RNA was extracted from islets with TRIzol (Invitrogen, Life Technologies, Gaithersburg, MD, USA) and treated with DNAse (Ambion, Houston, TX, USA). RNA samples were pooled (three to five animals per condition) and purified with RNeasy Minelute Cleanup (Qiagen, Hilden, Germany). RNA integrity was assessed by electrophoresis in a denaturing $1 \%$ agarose gel. Fifteen micrograms of total RNA were reverse transcribed and directly labelled with Cy3- or Cy5-nucleotides with a CyScribe First Strand cDNA labelling kit (Amersham Biosciences, Freiburg, Germany). Labelled cDNA was purified in a CyScribe GFX column (Amersham Biosciences). Escherichia coli transcripts (Memorec; Miltenyi Biotec, Cologne, Germany) were included in the reverse transcription reaction as controls of the labelling process. Labelled cDNAs were hybridised in cDNA microarrays (Memorec) designed by our group with 200 diabetes and autoimmunity-related genes, spotted $\times 4$. Hybridisations were performed at $62^{\circ} \mathrm{C}$ for $16 \mathrm{~h}$ following the manufacturer's instructions. After washing, microarrays were scanned (ScanArray 4000; GSI Lumonics, Boston, MA, USA) and normalised to E. coli control spots using QuantArray software (GSI Lumonics). Hybridisations were performed in triplicate, including a dye-swap. To test for statistical significance, data were expressed as the mean value of the $\log _{2}$ ratio between normalised intensities of samples from transgenic islets and from wild-type islets. Differential expression was considered significant when the $p$ value for a one-sample $t$-test was $<0.01$, considering all spots ( $n=12$ spots, three arrays with four internal replicate spots per array, passing normality test).

\section{Laser-capture microdissection}

A laser-capture microdissection technique was performed to obtain islets from diabetic mice which were very difficult to hand pick. Pancreatic cryostat sections $(6 \mu \mathrm{m})$ were settled on P.A.L.M. slides (P.A.L.M. Microlaser Technologies, Bernried, Germany) and stained with $\mathrm{H} / \mathrm{E}$. Islets were microdissected (P.A.L.M. Microlaser Technologies) on a Zeiss microscope.

\section{Real-time RT-PCR}

RNA was extracted from islets (hand-picked or microdissected) with RNeasy Micro (Qiagen). RNA from NIT-1 cells was extracted with TRIzol reagent (Invitrogen) and treated with DNAse (Ambion). RNA was denatured and random hexamer was added. Then, RNA from hand-picked islets was reverse transcribed by using Moloney murine leukaemia virus (MMLV) reverse transcriptase $(200 \mathrm{U} / \mu \mathrm{l}$; Promega, Southampton, $\mathrm{UK}$ ) in a reaction including
MMLV $1 \times$ RT-buffer, $1 \mathrm{mmol} / 1 \mathrm{dNTPs}$ and RNAsin (40 U/ $\mu \mathrm{l})$ (Promega). RNA from microdissected islets was reverse transcribed by using SuperScript II (200 U/ $\mu \mathrm{l})$ (Invitrogen) in a reaction including $1 \times$ RT-buffer, $10 \mathrm{mmol} / 1$ dithiothreitol, $2 \mathrm{mmol} / \mathrm{l} \mathrm{dNTPs}$ and RNAsin (40 U/ $\mu \mathrm{l}$ ) (Promega) at $42^{\circ} \mathrm{C}$ and $70^{\circ} \mathrm{C}$ for 60 and $15 \mathrm{~min}$, respectively. Real-time PCR was performed using an ABI 7900 System (Applied Biosystems, Foster City, CA, USA) using Taqman primers and probes for Reg1, Reg2, Il6, Ins2, Rn18s and Gapdh. Relative values were determined by normalising the expression for each gene of interest to a housekeeping gene (Rn18s or Gapdh) and to a calibrator sample (mRNA from islets from NOD-SCID mice or untreated NIT-1 cells), as described in the $2^{-\Delta \Delta \mathrm{Ct}}$ method [30].

Morphological analysis

The islet area from CD-1, NOD and NOD-SCID mice ( 4 weeks old, $n=12$ transgenic mice and $n=10$ controls) was assessed by the point-count method as reported elsewhere [31] and analysed in an image analyser (OpenLab 2.0; Improvision, Coventry, UK). Pancreatic sections (5 $\mu \mathrm{m})$ were stained with $\mathrm{H} / \mathrm{E}$. Islet area was determined (OpenLab 2.0) only taking into account the endocrine tissue. A minimum of 20 islets per animal was analysed. The size of beta cells was determined by measuring the area after specific staining with anti-glucagon, somatostatin and pancreatic polypeptide (Dako, Carpinteria, CA, USA) as described [32] in a minimum of 20 islets per condition.

Immunohistochemistry

Consecutive pancreatic cryostat sections $(5 \mu \mathrm{m})$ were sequentially stained by indirect immunofluorescence (IIF) with: (1) antibodies to REG1 (mouse monoclonal IgG2a [16] and REG2 (rabbit polyclonal IgG to REG2); (2) labelled goat anti-mouse Alexa 488 IgG2a (ICN, Aurora, $\mathrm{OH}, \mathrm{USA}$ ) or FITC-goat anti-rabbit (SBA); (3) guinea-pig anti-insulin (ICN) and (4) tetramethyl rhodamine isothiocyanate-labelled goat anti-guinea pig (ICN). The sections were observed in a fluorescence UV microscope and an image analyser (OpenLab 2.0). On cytosmears stained as described above, 100-200 beta cells-positive for insulin staining-were evaluated. To ensure specific staining of REG, control slides were stained without the primary antibody, which revealed no specific staining. Each IIF staining was performed in triplicate.

\section{Statistical analysis}

Data are expressed as means \pm SE. Statistical analyses to compare independent groups were performed using a $t$-test when groups passed normality and showed equal variance 
tests. Otherwise, a Mann-Whitney $U$-test was performed. Differences were considered significant when a value of $<0.05$ was reached $(p<0.01$ for microarray experiments).

\section{Results}

Reg2 mRNA is upregulated in NOD RIP-HuIFN $\beta$ islets

To determine the effect of IFN $\beta$ in the islets, we compared gene expression in islets from NOD RIP-HuIFN $\beta$ mice with those from NOD mice at the age of 4 weeks, at the onset of the autoimmune attack. The cDNA microarray analysis showed that Reg2 expression was higher in healthy NOD RIP-HuIFN $\beta$ when compared with non-transgenic littermates $(p<0.0001)$. As expected, $B 2 m$ expression was also increased $(p<0.01)$ (data from three independent experiments) (Table 1). However, other genes of autoantigens (Gad1, Gad2 and Insl) were not upregulated in transgenic animals (Table 1). Moreover, the gene expression of other islet molecules was not increased (glucagon, somatostatin and pancreatic polypeptide; data not shown). Reg2 upregulation was confirmed by quantitative RT-PCR (Fig. 1): Reg2 was 3.5-fold upregulated $(p<0.001)$ in NOD RIP-HuIFN $\beta$ when compared with NOD wild-type at the age of 4 weeks. Reg2 upregulation was not detected in 14week-old NOD mice when compared with 4-week-old healthy NOD mice (data not shown). Regl was not altered (results from three different experiments).

Reg2 overexpression in diabetic RIP-HuIFN $\beta$ mice

Islets from diabetic mice were obtained by laser-capture microdissection. RNA from microdissected islets was obtained for real-time RT-PCR. Reg2 was overexpressed in islets from early-onset diabetic RIP-HuIFN $\beta$ transgenic mice when compared with diabetic NOD mice (14.1-fold change, $p<0.05$ ) (Fig. 2). Reg1 mRNA increase (3.4-fold) was not statistically significant. Since REG induces beta cell proliferation, Ins2 expression was also determined. Ins 2 expression was higher in the islets from diabetic NOD

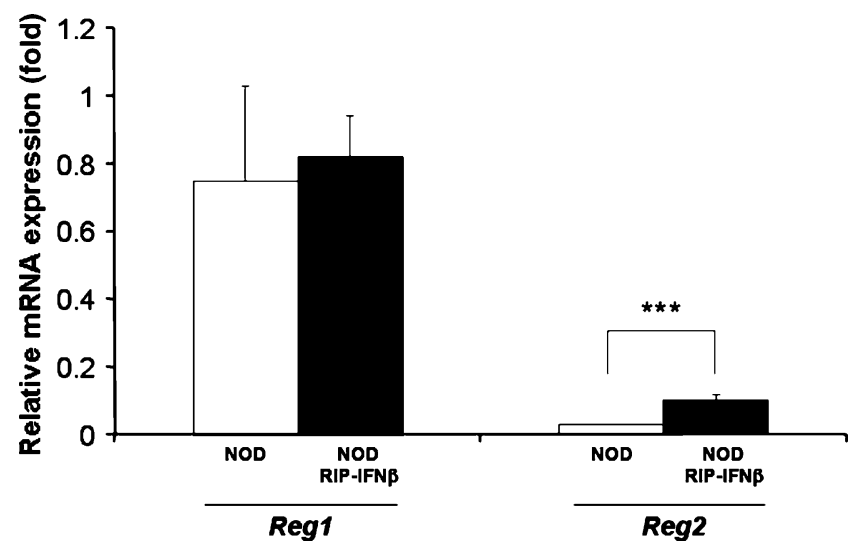

Fig. 1 Histogram of quantitative RT-PCR for Reg1 and Reg2 expression in islets from NOD (white bars) and NOD RIP-HuIFN $\beta$ (black bars) non-diabetic mice (4 week old). Results from three experiments expressed as the relative mRNA expression of Reg to Gapdh compared with a calibrator sample (NOD-SCID islets). The $2^{-\Delta \Delta \mathrm{Ct}}$ method was followed. $* * * p<0.001$

transgenic mice than in the islets from diabetic NOD wildtype (10.9-fold change, $p<0.05$ ), correlating with $\operatorname{Reg} 2$ overexpression.

REG1 and REG2: immunohistology of the islets

We detected a clear increase of REG1 and REG2 expression in the islets from healthy NOD RIP-HuIFN $\beta$ compared with healthy NOD mice at the age of 4 weeks (Fig. 3a). REG expression was markedly increased in diabetic transgenic mice compared with NOD diabetic mice. A weak increase in REG expression was also observed in the exocrine tissue from NOD RIP-HuIFN $\beta$ in close contact with the islets. As positive control of the effect of HuIFN $\beta$, we determined the MHC class I hyperexpression in the islets from NOD RIP-HuIFN $\beta$ as described elsewhere [8]. In order to correlate REG overexpression with the insulitis score, we compared the staining pattern in healthy NOD animals with advanced insulitis (14 weeks of age) with that of NOD mice with early insulitis (4 weeks of age), but no differences were found; this was in agreement with our microarray results (data not shown). Moreover, REG2 expression was slightly

Table 1 Microarray experiments: gene expression in islets from NOD RIP-HuIFN $\beta$ compared with NOD

\begin{tabular}{lllll}
\hline UniGene code & Gene symbol & $\log _{2}$ ratio (mean \pm SE) & $p$ value & Function \\
\hline Mm. 46360 & Reg2 & $3.48 \pm 0.14$ & $<0.0001$ & Beta cell proliferation factor. Autoantigen in type 1 diabetes \\
Mm. 163 & B2m & $1.43 \pm 0.33$ & 0.0034 & Antigenic presentation restricted to MHC I ( $\beta 2$-microglobulin) \\
Mm. 16620 & Gad1 & $0.17 \pm 0.22$ & NS & GAD. Autoantigen in type 1 diabetes \\
Mm. 4784 & Gad2 & $-0.31 \pm 0.24$ & 0.23 & GAD. Autoantigen in type 1 diabetes \\
Mm. 46269 & Ins1 & $-0.47 \pm 0.07$ & $<0.0001$ & Regulator of glucose metabolism. Autoantigen in type 1 diabetes \\
Mm. 5289 & Gapdh & $-0.26 \pm 0.10$ & NS & Housekeeping gene \\
\hline
\end{tabular}

All subjects were female, non-diabetic 4-week-old mice. Data are expressed as the mean of the $\log _{2}$ ratio between both samples. Differential expression was considered when the $p$ value for a one-sample $t$-test was $<0.01$ ( $n=12$ spots, four from each of three different experiments) 


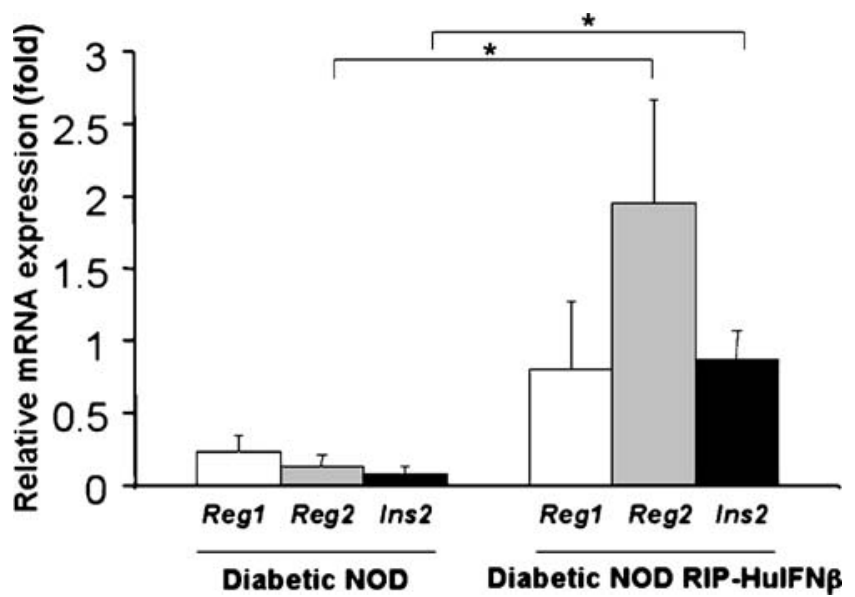

Fig. 2 Histogram of quantitative RT-PCR for Reg1 and Reg2 expression in microdissected islets from recent-onset diabetic mice (NOD and NOD RIP-HuIFN $\beta$ ). Reg1 (white bars), Reg2 (grey bars) and Ins2 (black bars) expression was normalised to that of Rn18s RNA, and NOD-SCID islets were used as a calibrator. Results from three independent experiments. The $2^{-\Delta \Delta \mathrm{Ct}}$ method was followed. $* p<0.05$

increased in the islets from NOD-SCID RIP-HuIFN $\beta$ mice compared with wild-type NOD-SCID mice (Fig. 3a). These mice have neither insulitis nor diabetes, due to their lack of functional lymphocytes, but hyperexpress MHC class I in the islets due to the effect of IFN $\beta$. In general, the staining pattern of REG agrees with that of insulin. To confirm colocalisation of REG and insulin, single islet cells were stained in cytosmears. REG2 and REG1 expression clearly co-localised to insulin staining (Fig. 3b), as described [16].

Insulitis is not the only cause of Reg2 hyperexpression

Since inflammation upregulates Reg expression, we assessed insulitis score. Insulitis score was statistically significantly higher in 4-week-old healthy NOD RIPHuIFN $\beta$ when compared with 4-week-old NOD mice $(p<0.001)$, and was well correlated with Reg2 induction (Fig. 4). However, insulitis was higher in 14-week-old NOD mice when compared with 4-week-old NOD mice $(p<0.05)$, but Reg2 upregulation was not found when both groups of animals were compared.

\section{Effect of IFN $\beta$ per se on Reg expression}

To confirm the effect of IFN $\beta$ on Reg expression, the NOD insulinoma cell line NIT-1 was cultured with HuIFN $\beta$. The effect of the cytokine on NIT-1 cells was confirmed by
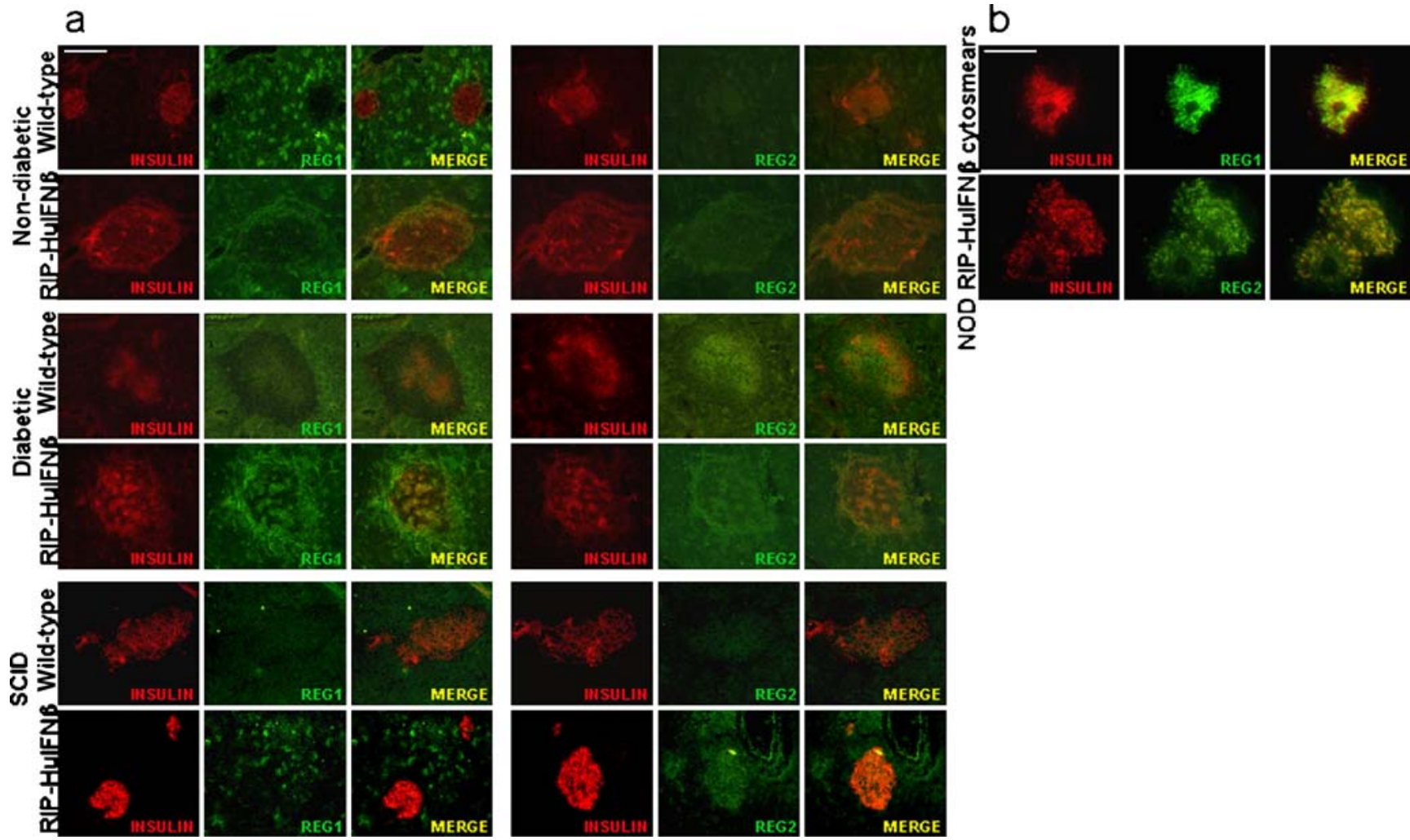

Fig. 3 REG1 and REG2 levels in the pancreatic islets. a Double IIF staining for REG (green) and insulin (red). REG1 (left panels) and REG2 (right panels) production in islets from NOD RIP-HuIFN $\beta$ mice, as compared with those from NOD and NOD-SCID mice.
Magnification: $\times 200$; the bar represents $100 \mu \mathrm{m}$. b Double IIF staining in isolated beta cells from non-hyperglycaemic NOD RIPHuIFN $\beta$ mice. REG1 and REG2 levels (green) in insulin-positive cells (red). Magnification: $\times 1,000$; the bar represents $25 \mu \mathrm{m}$ 


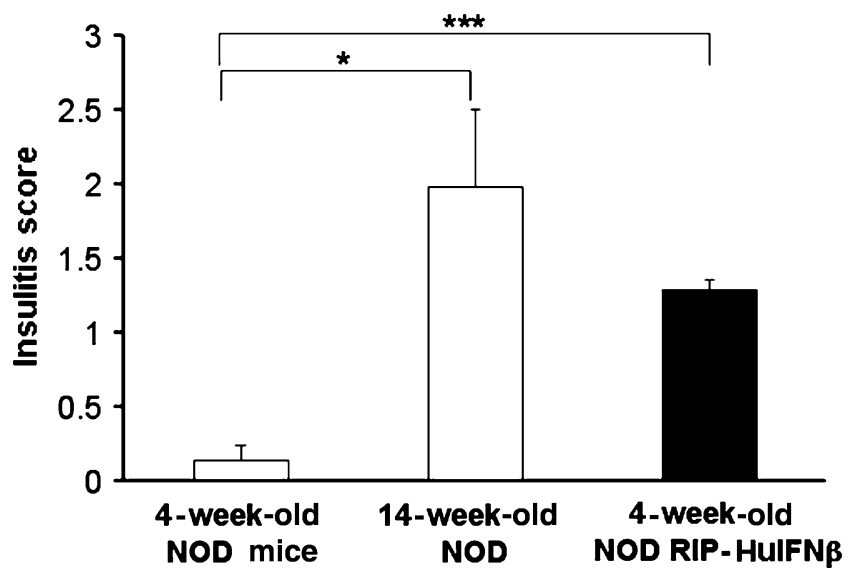

Fig. 4 Insulitis score in NOD (white bars) and NOD RIP-HuIFN $\beta$ (black bars) mice at the points studied by cDNA microarray analysis (3-6 animals per condition and 20 islets per animal). Islets from nonhyperglycaemic 14-week-old NOD females showed a significantly higher insulitis score $\left({ }^{*} p<0.05\right)$ than at 4 weeks. There was also a significant difference $(* * * p<0.001)$ between islet infiltration from NOD RIP-HuIFN $\beta$ mice and wild-type NOD mice at the age of 4 weeks

assessing MHC class I overexpression in the membrane of NIT-1 cells (100.2 \pm 19.6$)$, which increased significantly after culturing with HuIFN $\beta(439.4 \pm 43)(p<0.001)$. Quantitative RT-PCR showed that HuIFN $\beta$ upregulates the expression of Reg1 (3.1-fold change, $p<0.05$ ) and Reg2 (5.5-fold change, $p<0.001$ ) (Fig. 5) in the NIT-1 cell line (data from four independent experiments). Moreover, we compared Reg expression in the islets from NOD-SCID

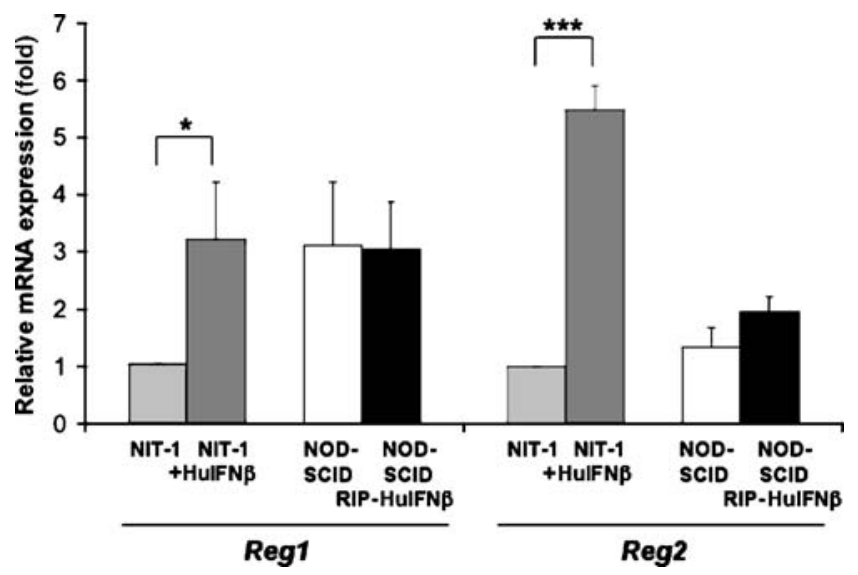

Fig. 5 Real-time RT-PCR analysis for Reg1 and Reg2 in the NIT-1 cell line and in NOD-SCID islets. Cells exposed to HuIFN $\beta$ for $72 \mathrm{~h}$ showed a 3.9- $(* p<0.05)$ and 5.48- $(* * * p<0.001)$ fold increase in Regl and Reg2 mRNA, respectively, when compared with basal cultured NIT-1 cells (data from four independent experiments). NODSCID RIP-HuIFN $\beta$ mice showed higher Reg2 expression than NODSCID mice, but differences were not statistically significant. Results were normalised to Gapdh expression and compared with a calibrator (untreated NIT-1 cells and NOD-SCID islets, respectively). Light grey bars, NIT-1 cells (basal); dark grey bars, NIT-1 cells with HuIFN $\beta$; white bars, NOD-SCID mice; black bars, islets from NOD-SCID RIPHuIFN $\beta$ transgenic mice
RIP-HuIFN $\beta$ and NOD-SCID. Islets from NOD-SCID RIP-HuIFN $\beta$ mice showed a slight Reg2 upregulation (Fig. 5) compared with NOD-SCID, although differences were not statistically significant (data from three experiments).

Upregulation of $I l 6$, a described enhancer of Reg promoter, by IFN $\beta$

As IFN $\beta$ increases IL-6 production [33], IL-6 acts as an enhancer in the upstream region of Reg genes [17], and inflammatory cytokines are produced in the insulitis, we determined $I l 6$ islet expression. NOD RIP-HuIFN $\beta$ transgenic mice overexpressed $I l 6$ in the islets $(12.1 \pm 1.8)$ when compared with islets from NOD wild-type mice $(2.8 \pm 0.8)$ (4.3-fold change, $p<0.001$, data from three independent experiments) (Fig. 6). To evaluate the effect of HuIFN $\beta$ while excluding that of insulitis, we measured $I l 6$ expression in the islets from NOD-SCID RIP-HuIFN $\beta$ and NOD-SCID mice. Islets from NOD-SCID RIP-HuIFN $\beta$ mice showed a slightly increased Il6 expression (Fig. 6) compared with NOD-SCID, although differences were not statistically significant (data from three experiments). The effect of HuIFN $\beta$ on $I l 6$ expression was determined in NIT- 1 cells: the expression of Il6 increased in NIT-1 cells exposed to HuIFN $\beta$ (2.5-fold change, $p<0.05$, data from four experiments). By using protein low-density arrays (a cytokine antibody array, a system to assess the expression profiles of multiple cytokines in pancreatic lysates; Raybiotech, Atlanta, GA, USA) we confirmed that the amounts of IL-6 in the pancreases from healthy and diabetic NOD RIP-HuIFN $\beta$

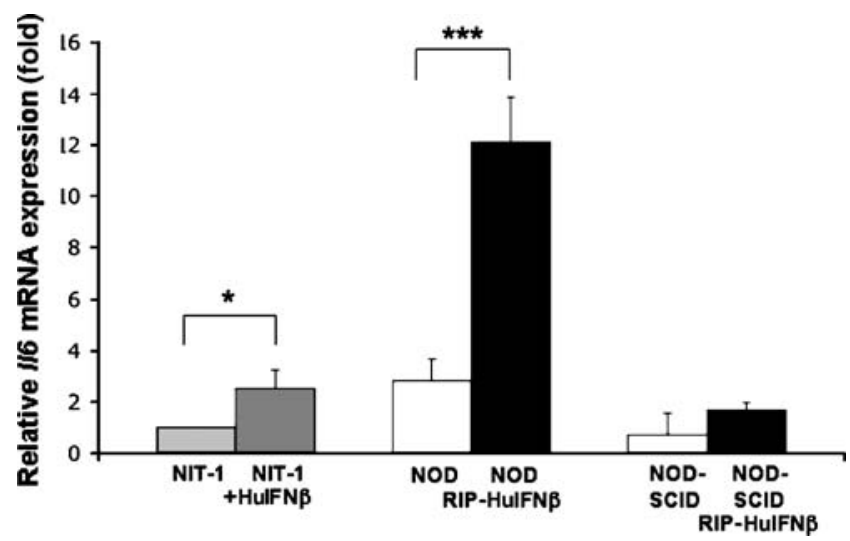

Fig. 6 Effect of IFN $\beta$ on Il6 mRNA expression. Real-time RT-PCR analysis for Il6 mRNA in NIT-1 cells (basal or cultured with HuIFN $\beta$ ), and in NOD and NOD-SCID mice (transgenic and wildtype). Il6 mRNA was significantly increased by IFN $\beta$ in NIT-1 cells $\left({ }^{*} p<0.05\right)$ and in NOD islets $(* * * p<0.001)$ (data from four and three independent experiments, respectively). Results were normalised to Gapdh expression and compared with a calibrator (untreated NIT-1 cells and NOD-SCID islets, respectively). Light grey bars, NIT-1 (basal); dark grey bars, NIT-1 with HuIFN $\beta$; white bars, NOD and NOD-SCID mice; black bars, NOD RIP-HuIFN $\beta$ and NOD-SCID RIP-HuIFN $\beta$ transgenic mice 
mice were higher that in wild-type mice by 1.9 - and 2.1-fold, respectively, (data not shown).

Enlarged islets in RIP-HuIFN $\beta$ mice

Since REG causes beta cell proliferation, we studied the endocrine area of the islets hyperexpressing REG. The area of the islets from NOD RIP-HuIFN $\beta$ mice, with mild insulitis, was $18,356 \pm 1,755 \mu \mathrm{m}^{2}, 33.8 \%$ larger than those of NOD wild-type mice $\left(13,717 \pm 1,532 \mu \mathrm{m}^{2}\right)(p<0.05)$. Moreover, the area of the islets from CD-1 RIP-HuIFN $\beta$, with peri-insulitis, was $17,231 \pm 770 \mu^{2}, 25 \%$ increased when compared with CD-1 wild-type mice $\left(12,686 \pm 543 \mu \mathrm{m}^{2}\right)$ $(p<0.01)$. Islets enlarged in $21 \%$ of the area $(17,315 \pm$ $1,354 \mu^{2}$ ) were also found in NOD-SCID RIP-HuIFN $\beta$ mice (insulitis-free) when compared with NOD-SCID mice $\left(14,304 \pm 1,139 \mu^{2}\right)(p<0.01)$ (Fig. 7a). Hence, we conclude that the increase of the islet area observed in transgenic mice
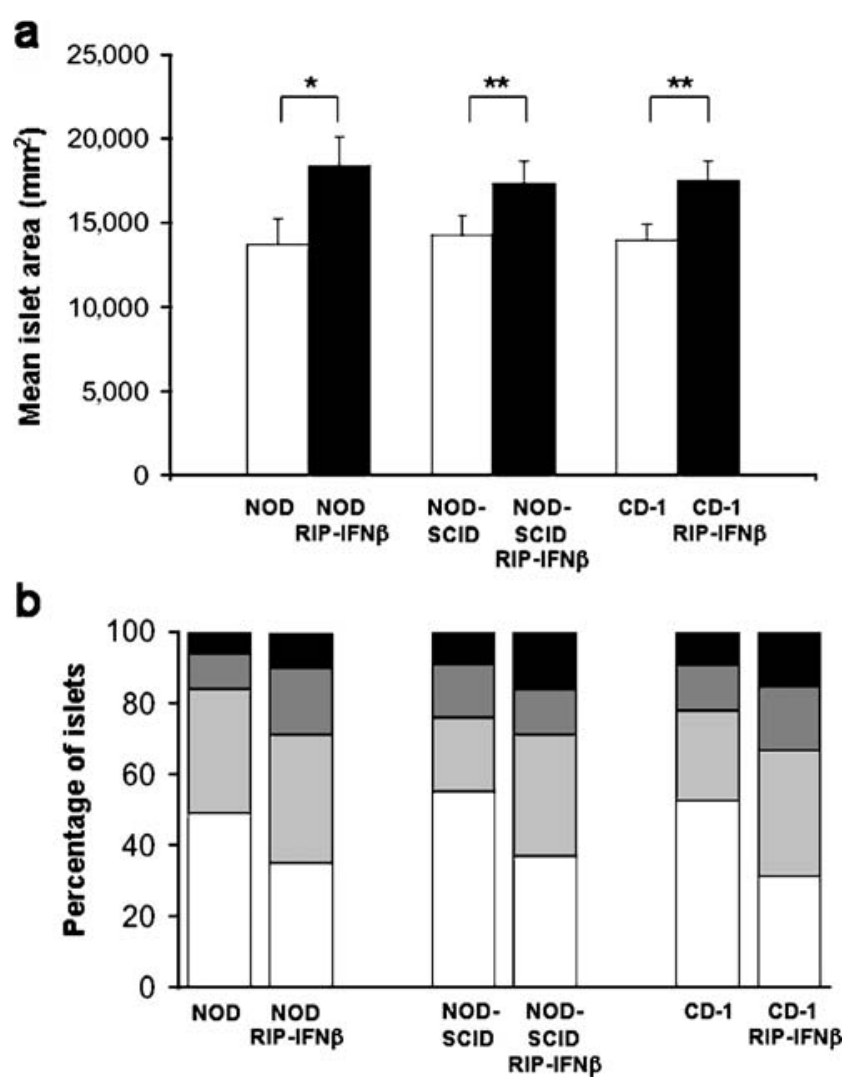

Fig. 7 Morphological studies. a Histogram of the mean of islet area $\left(\mu \mathrm{m}^{2}\right)$ in transgenic mice (black bars) and wild-type (white bars) NOD, NOD-SCID and CD-1 mice at the age of 4 weeks. A minimum of 20 islets/mouse was evaluated (three animals/condition). RIPHuIFN $\beta$ transgenic mice showed an increased islet area when compared with control $\left({ }^{*} p<0.05\right.$ and $\left.* * p<0.001\right)$. b Percentage of islets classified in each of the four area $\left(\mu \mathrm{m}^{2}\right)$ categories. A minimum of 20 islets/mouse was evaluated (three animals/condition) in NOD, NOD-SCID and CD-1 mice (RIP-HuIFN $\beta$ transgenic and control mice). White, small islets $\left(0-10,000 \mu \mathrm{m}^{2}\right)$; light grey, medium islets $\left(10,000-20,000 \mu \mathrm{m}^{2}\right)$; dark grey big islets $\left(20,000-30,000 \mu \mathrm{m}^{2}\right)$; black, mega islets $\left(>30,000 \mu \mathrm{m}^{2}\right)$ did not depend on the degree of insulitis but on the presence of IFN $\beta$. Transgenic mice, on the three genetic backgrounds studied, showed a lower percentage of small islets $\left(<10,000 \mu \mathrm{m}^{2}\right)$ and a higher percentage of large islets $\left(>20,000 \mu \mathrm{m}^{2}\right)$ (Fig. 7b). Moreover, the distribution of the islets in categories was similar in NOD, NOD-SCID and CD-1 mice. Thus, the expression of IFN $\beta$ in beta cells correlates with a higher percentage of large islets. The increase of the endocrine area may be caused by an increase in the beta cell size or in the islet cell number. No significant differences were found in the size of beta cells when comparing CD-1 transgenic mice with control mice (431 16.1 vs $407 \pm 15.7 \mu \mathrm{m}^{2}$ ). Moreover, beta cell density in the islets was the same in CD-1 RIP-HuIFN $\beta\left(988.4\right.$ cells $/ \mathrm{mm}^{2}$ ) as in wild-type mice $\left(988.3\right.$ cells $\left./ \mathrm{mm}^{2}\right)$. These data support the hypothesis that islet hyperplasia in transgenic mice is caused by an increase in the number of cells per islet. However, this islet hyperplasia did not cause any metabolic dysfunction; body weight, pancreatic weight, insulinaemia, pancreatic insulin contents and i.p. glucose tolerance tests were not altered in non-diabetic transgenic mice [8].

\section{Discussion}

The main finding of this study is Reg2 hyperexpression in the infiltrated islets from NOD RIP-HuIFN $\beta$ transgenic mice, correlating with islet enlargement and premature onset of diabetes: islets overexpress $\operatorname{Reg} 2$ both before and at the onset of the disease, but Reg1 expression did not increase significantly. Insulitis was not the only cause of this overexpression, because severely infiltrated islets from NOD mice did not hyperexpress Reg. The direct effect of IFN $\beta$ upregulating Reg1 and Reg2 was demonstrated in the NOD insulinoma cell line NIT-1. Reg2 hyperexpression associated with IFN $\beta$ always correlated with a relevant increase in IL-6, both in the islets from RIP-HuIFN $\beta$ transgenic mice and in NIT- 1 cell line, consistent with the described regulation of REG by IL- 6 . Moreover, mice with accelerated IFN $\beta$-driven diabetes showed higher levels of insulin than diabetic NOD mice, as expected in islets hyperexpressing Reg2. However, the increase in Reg1 and Reg2 observed in the islets from NOD-SCID RIP-HuIFN $\beta$ mice compared with NOD-SCID was not statistically significant. Interestingly, the islets from NOD RIP-HuIFN $\beta$ and NOD-SCID RIP-HuIFN $\beta$ transgenic mice displayed an increased area compared with wild-type mice. This islet hyperplasia did not cause a metabolic dysfunction of the beta cells.

The role of type 1 IFNs in autoimmunity has been discussed elsewhere [34]. This is the first report assessing the role of type 1 IFN in increasing the expression of REG, a diabetes autoantigen. The upregulation of Reg2 in NOD 
RIP-HuIFN $\beta$ transgenic mice could reflect the regeneration of beta cells during the autoimmune attack accelerated by the antiviral cytokine. Our results showed that IFN $\beta$ also increases IL- 6 in the beta cells. The correlation of IL- 6 and Reg2 hyperexpression observed in our model agrees with the previously reported IL-6 response elements in murine Reg genes $[10,14]$ and with the islet inflammation and hyperplasia detected in transgenic mice expressing IL-6 in the islet beta cells [35]. Since inflammation upregulates Reg expression, we assessed insulitis score. We conclude that insulitis is not the only cause of Reg2 hyperexpression, because old NOD mice did not hyperexpress Reg although they exhibited strong insulitis. Moreover, the islets from NOD-SCID RIP-HuIFN $\beta$ transgenic mice (insulitis-free) produced REG2 in the islets. Our results suggest that beta cell damage or stress is required for REG2 hyperexpression to promote cell growth or repair.

During a viral infection, IFN $\beta$ modulates inflammatory and immune responses by upregulating MHC I and $\mathrm{Il6}$ genes, among others [36]. The link between infections and type 1 diabetes has not been demonstrated, but infected islets themselves may produce inflammatory cytokines [37], affecting the clinical outcome of beta cell autoimmunity [38]. However, virally induced cytokines and chemokines can accelerate or prevent autoimmunity depending on the host strain, age, sex, immunological competence, time, location and level of expression. For example, another viral stimulus, the synthetic double-stranded RNA poly (I:C), inducer of IFN $\alpha$ and other cytokines, can either prevent or exacerbate the pathogenic effects of diabetogenic viruses, depending on the genetic background and the timing of administration [39, 40]. In our model, IFN $\beta$ expression in NOD islets results in an early onset of autoimmune diabetes. Since many virus-infected or stressed cells produce IFN $\beta$, our data suggest that Reg upregulation may regenerate beta cells that might accelerate the autoimmune process towards beta cells, contributing to an early onset of type 1 diabetes.

Since REG causes beta cell proliferation, we determined possible changes in islet morphology in transgenic mice. Enlarged islets were found in RIP-HuIFN $\beta$ transgenic mice. Mega islets have been associated with dendritic cells and macrophages and with beta cell activity [41]. Different factors may contribute to mega islet formation in RIPHuIFN $\beta$ mice: innate immunity, insulitis and beta cell damage/activity.

A transient attempt at beta cell regeneration was observed at the early stages of insulitis in NOD mice [41]. It has been reported that leucocytes influence endocrine cell growth [42]. The expression of Reg in the islets and ductal cells of prediabetic NOD mice [10], suggests that the early insulitis or the associated cytokines (IL-6, type I IFNs) may induce regeneration, also described in diabetic transgenic mice expressing IFN $\gamma$ in the islets [43] and in a cyclophospha- mide-induced type 1 diabetes model [44]. New beta cell formation and destruction has been found in long-standing type 1 diabetes patients, thus suggesting regeneration in chronic autoimmunity [45].

A REG family member has been described recently as an autoantigen in diabetes, but unlike other autoantigens, it seems to be upregulated during the prediabetic period [10]. Preliminary results from our group suggest that the response of islet-infiltrating $\mathrm{T}$ cells from transgenic (RIP-HuIFN $\beta$ ) and wild-type (NOD) mice to REG2, is higher than the response to GAD (data not shown), thus supporting the role of REG as an autoantigen. The expression of the most wellknown type 1 diabetes autoantigens is not upregulated at the beginning of the autoimmune process. Therefore, the autoimmune attack could be accelerated by the upregulation of Reg in the islets. After the clinical onset of type 1 diabetes, most patients enter a period of remission (honeymoon) as a consequence of diminished autoimmunity and/or of beta cell regeneration. Autoantibodies to REG have been found in diabetic patients and these autoantibodies may neutralise the proliferative effect of REG [11]. Whether Reg upregulation described in our model plays a key role both in regeneration and in diabetes onset remains to be determined.

In summary, the autoantigen REG overexpressed in islets from NOD RIP-HuIFN $\beta$ transgenic mice correlates with enlarged islets in non-diabetic animals and with an acceleration of diabetes onset. REG could provide novel molecular targets for the prognosis and progression of type 1 diabetes, for the recurrence of autoimmunity after pancreas or islet transplantation, and for the design of immunotherapy.

Acknowledgements This work was supported by the Spanish Ministry of Health (FIS 02/0107 and 04/1686 to M. Vives-Pi). R. Planas and A. Alba were supported by fellowships from the Instituto de Salud Carlos III (FI05/00418 and BEFI 01/9065), J. Verdaguer is associate professor of the Serra-Hunter Programme from the Catalan Government, and M. Vives-Pi is a researcher supported by FIS, Spanish Ministry of Health. We thank M. Taron and L. Perez (Hospital Germans Trias i Pujol, Badalona, Spain) for his help with quantitative RT-PCR, and V. Nacher (Autonomous University of Barcelona, Spain) for advising in morphology studies. We are grateful to E. Tolosa (University of Tübingen, Germany) for assistance with the microdissection technique.

Duality of interest None of the authors has any conflict of interest with regard to the information contained in this manuscript.

\section{References}

1. Bach JF, Chatenoud L (2001) Tolerance to islet autoantigens in type I diabetes. Annu Rev Immunol 19:131-161

2. Jun HS, Yoon JW (2003) A new look at viruses in type 1 diabetes. Diabetes Metab Res Rev 19:8-31

3. Maugh TH (1975) Diabetes: epidemiology suggests a viral connection. Science 188:347-351

4. Banatvala JE, Bryant J, Schernthaner G et al (1985) Coxsackie B, mumps, rubella and cytomegalovirus specific IgM responses in 
patients with insulin-dependent diabetes mellitus in Britain, Austria and Australia. Lancet 1:1409-1412

5. Foulis AK, Farquharson MA, Meager A (1987) Immunoreactive alpha interferon in insulin secreting beta cells in type 1 diabetes mellitus. Lancet 2:1423-1427

6. Somoza N, Vargas F, Roura-Mir C et al (1994) Pancreas in recent onset insulin-dependent diabetes mellitus. Changes in HLA, adhesion molecules and autoantigens, restricted $\mathrm{T}$ cell receptor $\mathrm{V}$ beta usage, and cytokine profile. J Immunol 153:1360-1377

7. Huang X, Yuang J, Goddard A et al (1995) Interferon expression in the pancreases of patients with type I diabetes. Diabetes 44:658-664

8. Alba A, Puertas MC, Carrillo J et al (2004) IFNbeta accelerates autoimmune type diabetes in nonobese diabetic mice and breaks the tolerance to beta cells in non-diabetes-prone mice. J Immunology 173:6667-6675

9. Anderson MS, Bluestone JA (2005) The NOD mouse: a model of immune dysregulation. Annu Rev Immunol 23:447-485

10. Gurr W, Yavari R, Wen L et al (2002) A Reg family protein is overexpressed in islets from a patient with new-onset type 1 diabetes and acts as T cell autoantigen in NOD mice. Diabetes 51:339-346

11. Shervani NJ, Takasawa S, Uchigata Y et al (2004) Autoantibodies to REG, a beta-cell regeneration factor, in diabetic patients. Eur J Clin Invest 34:752-758

12. Terazono K, Yamamoto H, Takasawa S et al (1988) A novel gene activated in regenerating islets. J Biol Chem 263:2111-2114

13. Zhang YW, Ding LS, Lai MD (2003) Reg gene family and human diseases. World J Gastroenterol 9:2635-2641

14. Sekikawa A, Fukui H, Fujii S et al (2005) Possible role of REG I alpha protein in ulcerative colitis and colitic cancer. Gut 54:1437-1444

15. Ogawa H, Fukushima K, Naito $H$ et al (2003) Increased expression of HIP/PAP and regenerating gene III in human inflammatory bowel disease and a murine bacterial reconstitution model. Inflamm Bowel Dis 9:162-170

16. Terazono K, Uchiyama Y, Ide M et al (1990) Expression of Reg protein in rat regenerating islets and its co-localisation with insulin in the beta cell secretory granules. Diabetologia 33:250-252

17. Okamoto H (1999) The Reg gene family and Reg proteins: with special attention to the regeneration of pancreatic beta cells. J Hepatobiliary Pancreat Surg 6:254-262

18. Watanabe T, Yonemura Y, Yonekura H et al (1994) Pancreatic beta cell replication and amelioration of surgical diabetes by Reg protein. Proc Natl Acad Sci USA 91:3589-3592

19. Unno M, Nata K, Noguchi $N$ et al (2002) Production and characterisation of Reg knockout mice. Diabetes 51(Suppl 3): S478-S483

20. Gross DJ, Weiss L, Reibstein I et al (1998) Amelioration of diabetes in nonobese diabetic mice with advanced disease by linomide induced immunoregulation combined with Reg protein treatment. Endocrinology 139:2369-2374

21. Qiu L, List EO, Kopchick JJ (2005) Differentially expressed proteins in the pancreas of diet induced diabetic mice. Mol Cell Proteomics 4:1311-1318

22. Yoshino N, Ishihara S, Rumi MA et al (2005) Interleukin-8 regulates expression of Reg protein in Helicobacter pylori-infected gastric mucosa. Am J Gastroenterol 100:2157-2166

23. Hamaguchi K, Gaskins HR, Leiter EH (1991) NIT-1, a pancreatic $\beta$-cell line established from a transgenic NOD/Lt mouse. Diabetes 40:842-849

24. Dhib-Jalbut SS, Cowan EP (1993) Direct evidence that interferonbeta mediates enhanced HLA-class I expression in measles virusinfected cells. J Immunol 151:6248-6258

25. Pelegrin M, Devedjian DJ, Costa C et al (1998) Evidence from transgenic mice that interferon-beta may be involved in the onset of diabetes mellitus. J Biol Chem 20:12332-12340
26. Prochazka M, Gaskins HR, Shultz LD, Leiter EH (1992) The nonobese diabetic SCID mouse: model for spontaneous thymomagenesis associated immunodeficiency. Proc Natl Acad Sci USA 89:3290-3294

27. Serreze DV, Fleming SA, Chapman HD, Richard SD, Leiter EH, Tisch RM (1998) B lymphocytes are critical antigen-presenting cells for the initiation of $\mathrm{T}$ cell-mediated autoimmune diabetes in non obese diabetic mice. J Immunol 161:3912-3918

28. Vargas F, García-Cuyás F, Julián JF et al (2001) Engraftment of islets obtained by collagenase and liberase in diabetic rats: a comparative study. Pancreas 23:406-413

29. Vives-Pi M, Somoza N, Vargas F et al (1993) Expression of glutamic acid decarboxylase (GAD) in the alpha, beta and delta cells of normal and diabetic pancreas: implications for the pathogenesis of type 1 diabetes. Clin Exp Immunol 92:391-396

30. Livak KJ, Schmittgen TD (2001) Analysis of relative gene expression using real-time quantitative PCR and the $2^{-\Delta \Delta C t}$ method. Methods 25:402-408

31. Yonemura Y, Takashima T, Miwa K, Miyazaki I, Yamamoto H, Okamoto H (1984) Amelioration of diabetes mellitus in partially depancreatised rats by poly (ADP-ribose) synthetase inhibitors: evidence of islet beta-cell regeneration. Diabetes 33:401-404

32. Montanya E, Nacher V, Biarnes M, Soler J (2000) Linear correlation between beta cell mass and body weight throughout the lifespan in Lewis rats. Diabetes 49:1341-1346

33. Brod SA, Marshall GD Jr, Henninger EM, Sriram S, Khan M, Wolinsky JS (1996) Interferon-beta 1b treatment decreases tumor necrosis factor-alpha and increases interleukin-6 production in multiple sclerosis. Neurology 46:1633-1638

34. Theofilopoulos AN, Baccala R, Beutler B, Kono DH (2005) Type I interferons in immunity and autoimmunity. Annu Rev Immunol 23:307-335

35. Campbell IL, Hoobs MV, Dockter J et al (1994) Islet inflammation and hyperplasia induced by the pancreatic islet-specific overexpression of interleukin-6 in transgenic mice. Am J Pathol 145:157-166

36. Der SD, Zhou A, Williams BRG, Silverman RH (1998) Identification of genes differentially regulated by interferon alpha, beta or gamma using oligonucleotide arrays. Proc Natl Acad Sci USA 95:15623-15628

37. Campbell IL, Curti A, Wilson A, Harrison LC (1989) Evidence for IL6: production by and effects on the pancreatic beta cells. J Immunol 143:1188-1191

38. Filippi C, von Herrath M (2005) How viral infections affect the autoimmune process leading to type 1 diabetes. Cell Immunol 233:125-132

39. Serreze DW, Hamaguchi K, Leiter EH (1989) Immunostimulation circumvents diabetes in NOD/Lt mice. J Autoimmun 2:759-776

40. Sobel DO, Goyal D, Ahvazi B et al (1998) Low dose poly I:C prevents diabetes in the diabetes prone BB rat. J Autoimmun $11: 343-352$

41. Rosmalen JGM, Leenen PJM, Pelegri C, Drexhage HA, HomoDelarche F (2000) Islet abnormalities associated with an early influx of dendritic cells and macrophages in NOD and NODscid mice. Lab Invest 80:769-777

42. Simons PJ, Delemarre FG, Drexhage HA (1998) Antigen presenting dendritic cells as regulators of the growth of thyrocytes: a role of interleukin-1 beta and interleukin-6. Endocrinology 139:3148-3156

43. Gu D, Sarvetnik N (1993) Epithelial cell proliferation and islet neogenesis in IFN-gamma transgenic mice. Development 118:33-46

44. Matos M, Park, Mathis D, Benoist C (2004) Progression to islet destruction. Diabetes 53:2310-2321

45. Meier JJ, Bhushan A, Butler AE, Risza RA, Butler PC (2005) Sustained beta cell apoptosis in patients with long-standing type 1 diabetes: indirect evidence for islet regeneration? Diabetologia 48:2221-2228 